* Doutor e Mestre em Direito do Estado pela Pontifícia Universidade Católica de São Paulo (PUC-SP). Professor cursos de Graduação, Especialização e Mestrado da Universidade Estadual de Londrina (UEL). E-mail: marcosstriquer@uol.com.br.

** Mestre em Direito Negocial pela Universidade Estadual de Londrina (UEL). Especialista em Direito Civil e Processo Civil pela Universidade Estadual de Londrina (UEL). Especialista em Direito Tributário pela Universidade Anhanguera (UNIDERP). E-mail: renataczqueiroz@ gmail.com.

\section{A Superação do Paradigma Clássico Do Negócio Jurídico: LiberalisMo E REPUBLICANISMO}

Overcoming the Classic Paradigm of LEgal TRANSACTIONS: LIBERALISM AND REPUBLICANISM

\section{Marcos Antônio Striquer Soares* Renata Capriolli Zocatelli Queiroz Passi**}

Como citar: SOARES, Marcos Antônio Striquer; PASSI, Renata Capriolli Zocatelli Queiroz. A superação do paradigma clássico do negócio jurídico: liberalismo e republicanismo. Scientia Iuris, Londrina, v. 21, n. 1, p.245-268, mar. 2017. DOI: $10.5433 / 2178-8189.2017 \mathrm{v} 21$ n1p245. ISSN: 2178-8189.

Resumo: Tenta-se resolver em qual modelo de liberdade, republicana ou liberal, o direito contratual brasileiro se baseia. Utilizou-se o método de revisão literária, pautado na construção teórico-científica fazendo um recorte no modelo filosófico da liberdade e no direito contratual pátrio. Para melhor compreensão, o artigo trabalha com a superação do paradigma do negócio jurídico clássico pelo moderno. No terceiro capítulo o artigo analisa cada paradigma fazendo uma ligação da concepção clássica e moderna com a liberal e republicana de 
liberdade. Assim, ficou evidenciado que o direito contratual do ordenamento jurídico brasileiro possuía como fundamento no paradigma clássico uma visão liberal de liberdade, porém com a superação do paradigma clássico pelo moderno percebe-se que é possível justificar a tutela dos direitos estatuídos pela Constituição Federal e absorvidos pelo direito civil brasileiro na perspectiva liberal tanto quanto na republicana, conforme demonstrado no trabalho.

Palavras-chave: Liberdade. Direito contratual brasileiro. Liberalismo. Republicanismo.

Abstract: This study analyzes Brazilian Contractual Law and the underpinnings of freedom - a characteristic of contracts. Furthermore, this paper fully utilizes the literature review method, focusing on the theoretical-scientific construction and the philosophical model of freedom in Brazilian Contractual Law. Likewise, to understand comprehensively this theme, this research paper employs the modern paradigm of legal transactions over the classical one. Nonetheless, this study explores both paradigms, linking them to the liberal and republican notions of liberty. Finally, this paper notes that the foundation of Brazilian Contractual Law is the classical paradigm - previously mentioned as the liberal perception of freedom. However, with the modern paradigm overtaking the old, the Brazilian Constitution gives rise to the protection of individual, social, and collective 
rights, which are incremented into the Brazilian Civil Code; therefore, this paper demonstrates that simultaneously there are these two notions with different views and ideals.

Keywords: Freedom. Brazilian contractual law. Liberalism. Republicanism. 


\section{INTRODUÇÃO}

O negócio jurídico é tema de fundamental relevância no estudo do direito e do ordenamento jurídico, pois, é através das regras pertinentes à sua formação que se concretizam os contratos da sociedade.

Como os negócios se fazem pela manifestação de vontade, isto é, pelo exercício da liberdade e como o modelo de liberdade, base dessa sociedade, influencia diretamente na formação e estrutura do negócio jurídico, no presente trabalho estudaram-se essas questões e seu relacionamento com o direito contratual do ordenamento jurídico brasileiro.

No primeiro capítulo trabalhou-se o conceito de liberdade segundo os modernos em confronto com a concepção liberal e republicana, a fim de esclarecer as questões concernentes ao conceito liberal e republicano do exercício da liberdade.

No segundo capítulo, o trabalho demonstrou a evolução do paradigma clássico do negócio jurídico, fundamentado no patrimonialismo e na individualidade. Demonstrou a evolução do paradigma clássico para o moderno no qual, não obstante, o cunho patrimonial ter sido mantido houve a constitucionalização do direito civil, ou seja, o exercício da liberdade ficou nesse momento balizado por direitos sociais.

Superada a questão do paradigma do negócio jurídico, no terceiro capítulo versou sobre a da superação do paradigma clássico e sobre a visão liberal a respeito da liberdade. Demonstrando, ainda, através das fundamentações apresentadas, as possíveis justificativas em virtude das quais se torna possível analisar o paradigma moderno de liberdade sob a ótica tanto do liberalismo, quanto do republicanismo. Conjuga, a seguir, o que trata neste capítulo com o tratado no primeiro 
capítulo, demonstrando que a tutela do negócio jurídico no ordenamento jurídico brasileiro, atualmente, pode ser justificada com base em ambas as concepções de liberdade.

\section{CONCEITO DE LIBERDADE E A CONCEPÇÃO LIBERAL E REPUBLICANA}

O conceito de liberdade modificou-se ao longo do tempo. Como consequência da evolução do modo de viver em sociedade. Os povos antigos devido a sua organização, cultivavam um tipo de liberdade diverso deste que o atual sistema político-social propõe a humanidade:

Aquela consistia em exercer coletiva, mas diariamente, várias partes da soberania inteira, em deliberar na praça pública sobre a guerra e a paz, em concluir com os estrangeiros tratados de aliança, em votar as leis, em pronunciar julgamentos, em examinar as contas, os atos, a gestão dos magistrados; em fazê-los comparecer diante de todo um povo, em acusa-los de delitos, em condená-los ou absolve-los; mas, ao mesmo tempo em que consistia nisso o que os antigos chamavam de liberdade, eles admitiam, como compatível com ela, a submissão completa do indivíduo à autoridade do todo (CONSTANT, 1985, p. 11).

Graças ao exposto, é possível perceber que o conceito de liberdade dos antigos não tem qualquer semelhança com o conceito de liberdade dos modernos. Para melhor mostrar a entre ambos os conceitos de liberdade, o texto que segue demonstra quão diferente ela é do texto supracitado, em relação ao conceito de liberdade: 
É para cada um o direito de não se submeter senão às leis, de não poder ser preso, nem detido, nem condenado, nem maltratado de nenhuma maneira, pelo efeito da vontade arbitrária de um ou de vários indivíduos. É para cada um o direito de dizer sua opinião, de escolher seu trabalho e de exercê-lo; de dispor de sua propriedade, até abusar dela; de ir e vir, sem necessidade de permissão e sem ter que prestar conta de seus motivos ou de seus passos (CONSTANT, 1985, p. 10).

Ao comparar ambos os conceitos convém ressaltar a soberania do povo antigo em lidar com as questões públicas e a sua limitação no que tange aos assuntos privados. Assim: “Os objetivos dos antigos era a partilha do poder social entre todos os cidadãos de uma mesma pátria. Pois, os antigos quando sacrificavam essa independência aos direitos políticos, sacrificavam menos para obter mais; enquanto que, fazendo o mesmo sacrifício, nós daríamos mais para obter menos" (CONSTANT, 1985, p. 15).

Em contrapartida, “[...] a independência individual é a primeira das necessidades modernas" (CONSTANT, 1985, p. 19). Dessa forma, percebe-se a necessidade da atual sociedade em querer desfrutar de seus direitos como deseja, sem interferência das autoridades, bem como da religião (CONSTANT, 1985, p. 21).

Diante dessa constatação, justifica-se o estudo da noção negativa de liberdade, a qual reflete a postura de muitas sociedades dos tempos hodiernos.

A concepção liberal negativa de liberdade foi representada, no início, como um direito racional da natureza humana que, aplicado às ações humanas, se define como a ausência de impedimentos externos que 
impossibilitariam ao indivíduo agir conforme deseja (RAMOS, 2007, p. 305). De acordo com a concepção liberal, assim se define o conceito de ser livre:

Ser livre significa não sofrer a interferência de outrem e fazer tudo aquilo que as leis permitem. Esta liberdade pressupõe um espaço de não ingerência, de ausência de impedimentos ou de obstáculos (por isso ela é chamada de negativa) para o exercício de ações que os indivíduos deliberadamente desejam realizar. No sentido positivo, a liberdade é compreendida como a capacidade de autodeterminação do indivíduo por meio da autonomia da vontade (RAMOS, 2007, p. 305).

No que se refere à concepção liberal, é possível perceber o aspecto negativo de liberdade. A liberdade negativa, segundo a visão liberal e no sentido político, é de acordo com Isaiah Berlim (2002, p. 229) o espaço que o homem possui para agir sem ser obstruído por outros.

O critério da opressão é o papel que acredito estar sendo desempenhado por outros seres humanos direta ou indiretamente, com ou sem intenção, para frustrar meus desejos. Ser livre, nesse sentido, para mim significa não sofrer a interferência dos outros. Quanto maior a área de não-interferência, mais ampla minha liberdade (BERLIM, 2002, p. 229).

Cesar Augusto Ramos dá explicações sobre a característica "negativa" atribuída a liberdade: "Ela é negativa porque limita a atuação dos indivíduos a uma esfera de ação que a lei permite, e cuja obediência requer o poder coercitivo (legítimo) do Estado para garantir o respeito recíproco dos agentes à liberdade" (RAMOS, 2007, p. 309). 
Percebe-se que o Estado, de acordo com o aspecto negativo da concepção liberal de liberdade, passa a ter o papel de impedir a invasão de direitos pelas ingerências dos cidadãos, e, também do próprio Estado:

Com o objetivo de garantir estes objetivos, a filosofia política do liberalismo acaba adotando um paradigma jurídico que estabelece procedimentos equitativos e imparciais na constituição e na defesa daquilo que é adequado (justo) para a sociedade. A lei pública constitui o meio mais adequado para assegurar a liberdade individual, o pluralismo ético, político e religioso, a diversidade das formas de vida, e a livre gestão privada dos interesses econômicos. $\mathrm{O}$ único "bem" possível que pode ser partilhado por todos é o direito (RAMOS, 2007, p. 309).

A concepção liberal de liberdade faculta ao indivíduo a liberdade necessária para agir de acordo com seu interesse, para realizar suas escolhas da forma que convém, como um ser racional que age, tem vontade e pensa. Além disso, é não só responsável pelas suas escolhas, mas também capaz de explica-las a partir de suas ideias e propósitos (BERLIM, 2002, p. 237).

Diferente da visão liberal, os republicanos possuem outra compreensão de liberdade. Para estes, liberdade é “"[...] ausência objetiva de domínio ou dependência, para que ela possa ser também um direito subjetivo ancorado na autonomia da vontade" (RAMOS, 2007, p. 313). Neste sentido Cesar Augusto Ramos (2007, p. 312) explica:

A concepção republicana de liberdade afirmar, portanto, que a verdadeira liberdade política não se restringe apenas à presença da não-dominação (ou da sua possibilidade) que cria no sujeito uma relação de dependência pessoal em relação à vontade de outro 
(s) indivíduo (s) ou instituições, mas deve haver também a ausência de interferência ou impedimentos de indivíduos ou instituições, naqueles atos em que os sujeitos desejam realizar e estão aptos para isso.

Assim, é possível concluir que, de acordo com a concepção republicana de liberdade o indivíduo passa a ser livre na medida em que não é dependente em dois aspectos, a saber: na ausência de interferência e na não dominação (RAMOS, 2007, p. 312).

Feitas essas considerações sobre o conceito liberal de liberdade, é válido ressaltar que a liberdade está diretamente atrelada à vontade, ou seja, o ser humano age na medida em que possui vontade e liberdade para agir.

Segundo Francisco do Amaral (2003, 216), a vontade aparece como um motor, que direciona e impulsiona o movimento em todos os reinos das faculdades dos seres humanos. Para o autor, conceitua-se liberdade conforme a possibilidade de manifestação da vontade:

A possibilidade de a pessoa agir de acordo com sua vontade, podendo fazer ou deixar de fazer algo, chama-se liberdade, que, sendo conceito plurívoco, extremamente complexo, compreende várias espécies, como a liberdade natural, a social ou a política, a pessoal e a jurídica, que é a que nos interessa (AMARAL, 2003, p. 215).

No âmbito do direito privado, a de liberdade que o agente possui para atuar chama-se autonomia, e traduz-se no direito de reger-se pelas próprias leis (AMARAL, 2003, p. 215). Como a autonomia guarda intima relação com o negócio jurídico - pois é através do exercício da autonomia que o negócio jurídico se concretiza, e o exercício da autonomia, no 
âmbito do direito privado, se transforma ao longo do tempo- sendo então oportuno o estudo dessa evolução, o que se fará no capítulo a seguir.

\section{A EVOLUÇÃO DO PARAGIDMA DO NEGÓCIO JURÍDICO - DO CLÁSSICO AO MODERNO}

Os fatos jurídicos produzem efeitos jurídicos que implicam o nascimento, a modificação ou a extinção de relações jurídicas. "Fatos jurídicos são, portanto aqueles factos a que o direito atribuiu relevância jurídica no sentido de mudar às situações anteriores a eles e de configurar novas situações, a que corresponde nova situação jurídica" (BETTI, 1969, p. 20). Podem ocorrer sem qualquer participação humana, são denominados fatos jurídicos em sentido estrito; são ordinários os fatos jurídicos, em sentido estrito como o nascimento, a morte, o decurso de tempo, e extraordinários os casos fortuitos ou os que ocorrem por força maior.

Quando há manifestação de vontade humana, classifica-se o fato jurídico como ato jurídico: são atos jurídicos em sentido estrito, aqueles cujos efeitos a serem produzidos já estão previstos na lei, como, por exemplo, o casamento, o reconhecimento de filho, entre outros.

Quando há declaração de vontade humana destinada a produzir determinado efeito, este denomina-se negócio jurídico, e é ele o instrumento da autonomia privada, e é "[...] constituído, portanto, em uma esfera de atuação do sujeito no âmbito do direito privado, mais propriamente em espaço que lhe é concedido para exercer a sua atividade jurídica. Os particulares se tornam, desse modo, nessas condições, legisladores sobre os seus próprios interesses" (AMARAL, 2003, p. 347). "Por negócio jurídico entende-se como declaração de vontade privada 
destinada a produzir efeitos que o agente pretende e o direito reconhece [...]" (AMARAL, 2003, p. 371), sendo, por conseguinte importante a manifestação da vontade do indivíduo.

Ao adentrar-se nos estudos dos paradigmas do negócio jurídico do ordenamento jurídico brasileiro, quando da observância do paradigma clássico, vê-se que a manifestação da vontade se dava através do exercício da autonomia da vontade, cuja base era fundada na sociedade liberal dos séculos XVIII e XIX, como fruto da revolução burguesa e garantia ao homem o livre e pleno exercício de suas vontades, sendo esse exercício respeitado pelo Estado.

Afirma Emílio Betti (1969, p. 99): “[...] na autonomia privada criadora de relações jurídicas, a ordem jurídica limita-se a reconhecer aos indivíduos o poder de criar fatiespécies capazes de gerar vínculos entre eles".

No Brasil, especialmente após a promulgação da Constituição Federal, iniciou-se o processo de superação do paradigma clássico, pois se passou a interpretar o direito civil à luz do direito constitucional. Houve, portanto a constitucionalização do direito civil, que proporcionou a superação do paradigma clássico pelo paradigma moderno. Sobre o assunto, Caio Mario da Silva Pereira (2013, p. 43) explica:

Tal proposta consolidou em nossa doutrina um direito civil-constitucional, isto é, um direito civil interpretado e aplicado à luz dos valores constitucionais, reconhecido nos meios acadêmicos e também pelos Tribunais. Na metodologia da interpretação do Código Civil destacam-se hoje os princípios constitucionais e os direitos fundamentais, os quais se impõem às relações interprivadas, aos interesses particulares, de modo a fazer prevalecer uma verdadeira "constitucionalização" do direito 
privado. Cabe, portanto, ao intérprete evidenciar a subordinação da norma de direito positivo a um conjunto de disposições com maior grau de generalização, isto é, a princípios e valores dos quais não pode ou não deve mais ser dissociada.

Dessa forma o conceito tido no paradigma moderno, passa a ser de autonomia privada, que consiste na faculdade que o indivíduo tem de regular, pelo exercício de sua vontade, as relações que ele cultiva. Possui como fundamento a liberdade, que lhe permite praticar ou não ato, desde que não seja proibido por lei. Francisco Amaral (2003, p. 352) ensina:

É o espaço livre que o ordenamento estatal deixa ao poder jurídico dos particulares, uma verdadeira esfera de atuação com eficácia jurídica, reconhecendo que, tratando-se de relações no direito privado, são os particulares os melhores, a saber, de seus interesses e da melhor forma de regulá-los juridicamente.

A partir daí aparece, no direito, o conceito de função entendido como o papel que a norma desempenha no ordenamento jurídico:

A referência à função social ou econômico-social, de um princípio, um instituto, uma categoria jurídica, neste caso a autonomia privada e seu instrumento de realização, o negócio jurídico, significa a aproximação do direito com as demais ciências sociais, como a sociologia, a economia, a ciência política, a antropologia, em um processo interdisciplinar de resposta às questões que a sociedade contemporânea apresenta ao jurista, considerando não mais como a figura tradicional de cultor do direito privado, ancorado aos dogmas das tradicionais características civilísticas, mas atento à realidade do seu tempo, a exigir-lhe uma postura crítica em prol de uma ordem 
mais justa na sociedade (AMARAL, 2003, p. 366).

A efetivação da autonomia privada requer o interesse do particular e da sociedade em ver eficácia nas normas e nos institutos não só no que se referte ao controle ou disciplina social, mas também na direção e organização de uma sociedade.

A partir daí, e em havendo a existência da função econômica social, que se manifesta na preocupação com a eficácia social do instituto, no caso da autonomia privada deve-se reconhecer que a livre circulação de bens e a prestação de serviços condicionam-se à utilidade social, que visa uma ordem social mais justa, tornando-se possível o desenvolvimento de um Estado moderno. A função social é:

[...] de um princípio geral, um verdadeiro standard jurídico, uma diretiva mais ou menos flexível, uma indicação programática que não lhe colide nem torna ineficaz os direitos subjetivos, orientando-lhes o respectivo exercício na direção mais consentânea com o bem comum e a justiça social. E é precisamente o contrato, instrumento da autonomia privada, o campo de maior aceitação dessa teoria [...] (AMARAL, 2003, p. 368).

Percebe-se então que a função econômica social dos institutos jurídicos limita o exercício da autonomia privada da seguinte forma, a saber, ela deve prezar pela ordem pública e pelos bons costumes, levando em conta especialmente a utilidade que possa advir com a consecução dos interesses gerais da comunidade, tendo como objetivo o desenvolvimento econômico e o bem-estar social. Sob essa perspectiva é possível afirmar que o direito se preocupa em exercer uma função corretora e de equilíbrio dos interesses nos diversos setores da sociedade. 
Diante do exposto, ao longo das transformações vividas pela sociedade, e conveniente se torna realizar uma análise sobre a evolução dos paradigmas do negócio jurídico ao longo do tempo em face das justificativas baseadas nas concepções liberais e republicanas do modelo de ordenamento jurídico adotado pelo país, que será objeto de estudo do capítulo a seguir.

\section{A SUPERAÇÃO DO PARADIGMA CLÁSSICO AO MODERNO: LIBERALISMO X REPUBLICANISMO}

Quanto à evolução do paradigma do negócio jurídico no ordenamento jurídico brasileiro constata-se que é necessário, em vista da transformação da sociedade, reler os institutos jurídicos de acordo com o modo de vida da sociedade em cada momento de sua história.

Tais transformações são frutos da postura humana em face da liberdade que o indivíduo possui para agir, sendo ela um atributo indispensável à configuração do próprio modo de ser do ser humano, conforme leciona Sergio Alves Gomes (2011, p. 208):

Em sendo a liberdade um atributo indispensável à configuração do próprio modo de ser humano em sua plenitude, a convivência em sociedade requer o convívio das múltiplas liberdades. Para que isso seja possível, é necessário limites que possibilitem a todos e a cada um o exercício da liberdade de forma responsável.

Por isso, é possível afirmar levando em conta o modo como o homem se posiciona perante à vida, que sua liberdade de escolha e a forma como a fundamenta, refletem diretamente no direito que tutela a 
sociedade na qual ele vive. Para demonstrar essa afirmação, passa-se à análise dos paradigmas do negócio jurídico, acima referidos, relacionados com os modelos liberal e republicano de liberdade, avaliando-se, desse modo, as interpretações possíveis para esses paradigmas.

\subsection{A autonomia privada diante do liberalismo e da república}

No paradigma clássico do negócio jurídico, via-se como importante a tradição patrimonialista, proclamada pelo Código Civil de 1916, no qual predominava a visão individual do direito dando-se, inclusive, força obrigatória aos pactos firmados.

Com a superação desse paradigma, a moderna dogmática civilista, conquanto tenham mantido, na essência, as relações patrimoniais, passa a fundamentar-se nos princípios estatuídos na Constituição Federal, os quais o direito à vida e à dignidade da pessoa humana. Percebe-se, portanto, uma nova perspectiva do direito, a qual deixa de lado o privilégio da individualidade e passa a ter, como novo foco, a promoção e preservação da dignidade da pessoa humana. Neste sentido Maria Celina Bodin de Moraes (1991, p. 4) expõe:

Diante da nova Constituição e da proliferação dos chamados microssistemas, como, por exemplo, a Lei do Direito Autoral, e recentemente, o Estatuto da Criança e do Adolescente, o Código de Defesa do Consumidor e a Lei das Locações, é forçoso reconhecer que o Código Civil não mais se encontra no centro das relações de direito privado. Tal polo foi deslocado, a partir da consciência da unidade do sistema e do respeito à hierarquia das fontes normativas, para a Constituição, base única dos princípios fundamentais do ordenamento. 
Sendo assim, no concernente ao formato de exercício da liberdade do paradigma moderno, que deve ser praticado de acordo com os limites estabelecidos em lei, convém afirmar que ele pode ser justificado tanto pela concepção liberal quanto pela concepção republicana.

Ao analisar-se o paradigma moderno do negócio jurídico sob a visão liberal de liberdade, vê-se que a proteção dada ao indivíduo pela Constituição Federal encontra fundamento na concepção negativa de liberdade, pois o conjunto dos direitos tutelados pela Constituição Federal protege o cidadão contra a interferência indevida de outrem ou do Estado, conforme Cesar Augusto Ramos (2007, p. 308) explica:

São liberdades que, definidas por direitos e deveres constitucionais, formam um conjunto articulado de meios e possibilidades legalmente protegidos que permitem aos cidadãos o direito de agir como desejam e impedem interferências indevidas dos outros ou do Estado.

Segundo esta visão, cumpre atentar para a Teoria de Justiça defendida por John Rawls, um liberal, a qual possui como fundamento o princípio da diferença:

O princípio da diferença representa, na verdade, um acordo para considerar a distribuição das aptidões naturais um bem comum e para compartilhar quaisquer benefícios que ela possa propiciar. Os mais favorecidos pela natureza, não importa quem sejam, só devem usufruir de sua boa sorte de maneiras que melhorem a situação dos menos favorecidos. Aqueles que se encontram naturalmente em posição vantajosa não devem ser beneficiados simplesmente por ser 
mais dotados, mas apenas para cobrir os custos com treinamento e educação e usar seus dotes de modo a ajudar também os menos afortunados. [...] A estrutura básica da sociedade pode ser elaborada de forma que essas contingências [maior capacidade natural de alguém] trabalhem para o bem dos menos afortunados (RAWLS, 1971 apud SANDEL 2012, p. 194).

Michael Sandel (2012, p. 179) explica que um dos princípios norteadores da Teoria da Justiça de John Rawls “"...] refere-se à equidade social e econômica. Embora não requeira uma distribuição igualitária de renda e riqueza, ele permite apenas as desigualdades sociais e econômicas que beneficiam os membros menos favorecidos de uma sociedade". Assim, é possível dizer, com base em John Rawls, que a concessão dos direitos abarcados pela Constituição Federal, os quais foram impressos no direito civil brasileiro com a superação do paradigma clássico do negócio jurídico pelo moderno, pode ser efetivada conforme a perspectiva liberal, pois, dessa forma a tutela dos direitos passou a trabalhar a igualdade no limite da desigualdade, fazendo com que os menos afortunados recebam benefícios. Mas esses benefícios recebidos são destinados a indivíduos, para que cada um possa ter uma vida melhor, elas não são destinadas à um todo.

Compreendida a justificativa liberal do paradigma moderno do negócio jurídico no ordenamento jurídico brasileiro, convém estudar a fundamentação republicana destinada à proteção de determinados direitos tutelados pela Constituição Federal. Para melhor compreender a justificativa republicana é imprescindível entender que o sentido republicano de liberdade é político. Sobre o tema Cesar Augusto Ramos (2007, p. 316) explica: 
O sentido republicano de liberdade é político, deduzido não da ideia tradicional de que a liberdade deve ser vista como autonomia de uma vontade autoreferente ou constituída a partir do vazio de atos de ingerência, mas como poder que o indivíduo tem de auto-afirmação na sua capacidade de resistência à dominação e ao perigo do domínio. Isso é possível, sobretudo, pelo fato dele ser considerado como pessoa e cidadão - na qualidade de membro de uma comunidade.

Confirmando-o, Cesar Augusto Ramos (2007, p. 315) afirma: "[...] constitui um pressuposto decisivo para o desenvolvimento afirmativo da teoria republicana da liberdade a incorporação do princípio aristotélico de que o homem é um animal naturale sociale e politicum". Ou seja, visto possuir, como essência, o ser social e político, o homem será livre na medida em que exercitar sua capacidade social e política.

Diante disso, é necessário se compreenda o propósito da política, a qual, segundo Aristóteles, não se destina a criar uma estrutura de direitos neutra em relação às finalidades, mas sim a formar bons cidadãos e cultivar o bom caráter:

Qualquer pólis que mereça ser assim chamada deve dedicar-se ao propósito de promover a bondade. Caso contrário, uma associação política reduir-se-á a uma mera aliança [...]. Caso contrário também, a lei será transformada em um mero pacto [...] uma garantia dos direitos dos homens contra seus semelhantes em vez de ser, como deveria, uma regra da vida para tornar seus membros bons e justos (ARISTÓTELES, 1280 apud SANDEL 2012, p. 240).

Quanto ao exercício da liberdade republicana, ele é possível 
somente na existência dos indivíduos em sociedade sendo suas relações institucionalizadas de maneira que tornam possível sua coexistência sem interferências:

Assim, a própria liberdade, embora individual, está atrelada à presença constitutiva e positiva do outro numa relação de reciprocidade. Ser livre significa estar protegido pela lei numa forma de vida social, na qual o reconhecimento da liberdade é possível porque todos pertencem a uma sociedade que tem como valor social a proteção das ações dos sujeitos, e que reconhecem a legitimidade destas ações e se abstêm de interferências (RAMOS, 2007, p. 317).

Por conseguinte, o republicanismo pensa a liberdade entendendo-a como liberdade de todos indiscriminadamente. Tal conceito de liberdade política implica o reconhecimento de outro conceito a ele conexo, o da igualdade:

O republicanismo não define a liberdade como um atributo humano produzido pela natureza, mas como uma forma de ação propiciada pelas instituições políticas, pelas quais a garantia contra a interferência dos outros se torna possível. A eficácia da liberdade é produzida por um sistema social e político republicano igualitário que garante leis impeditivas à ação abusiva do poder político, social ou econômico (RAMOS, 2007, p. 317).

Portanto, é possível perceber, que a concepção republicana enxerga, nas leis criadas pelos cidadãos através da política, a garantia da liberdade compreendida conforme já elucidado, que a liberdade, no sentido republicano de liberdade é política: 
Em terceiro lugar, a liberdade política do republicanismo implica, também, a ação de criar uma ordem ética e cívica que instaurando a igualdade e a submissão de todos à lei, torna-se instrumento de proteção de todos contra o infortúnio da servidão. Uma característica essencial do autogoverno, possível nas repúblicas como forma de poder político sob o qual uma comunidade pode obter grandeza e garantir aos seus cidadãos suas liberdades individuais (RAMOS, 2007, p. 319).

Ainda, sob o ponto de vista republicano dos, é possível justificar o fundamento do paradigma moderno com base na Teoria da Justiça do autor Michael Sandel (2012, p. 321), visto que esta teoria sustenta a ideia de que justiça envolve o cultivo da virtude e a preocupação com o bem comum.

Conforme exposto no segundo capítulo, ao paradigma moderno do negócio jurídico foram incorporados os direitos sociais introduzidos no ordenamento jurídico pela Constituição Federal. Michael Sandel (2012) afirma que uma sociedade justa deve preocupar-se com o todo. Veja-se o que ele diz:

Se uma sociedade justa requer um forte sentimento de comunidade, ela precisa encontrar uma forma de incutir nos cidadãos uma preocupação com o todo, uma dedicação ao bem comum. Ela não pode ser indiferente às atitudes e disposições, aos "hábitos do coração" que os cidadãos levam para a vida púbica, mas precisa encontrar meios de se afastar das noções da boa vida puramente egoístas e cultivar a virtude cívica (SANDEL, 2012, p. 325).

Na república, a pretensão é satisfazer o bem comum de todos 
os membros da comunidade. Diferentemente da posição liberal, que redistribui benefícios para que sujeitos menos favorecidos possam satisfazer interesses pessoais.

Contrapondo-se à justificativa liberal de John Rawls, acima referida, no que tange à redistribuição de rendas, Michael Sandel diz que a desigualdade corrói a virtude cívica, o que os liberais, preocupados com essa redistribuição, ignoram essa perda.

Para o autor, uma vez que os locais públicos, como escolas públicas, parques pátios, deixam de ser locais onde diferentes classes econômicas se encontram - o que ele define como esvaziamento - tal situação implica diretamente na dificuldade de cultivar o hábito da solidariedade e da boa convivência dos quais depende a cidadania democrática (SANDEL, 2012, p. 328). Assim, a Teoria da Justiça defendida por Michael Sandel (2012) expõe:

Uma política do bem comum teria como um dos seus principais objetivos a reconstrução da infraestrutura da vida cívica. Em vez de voltar para a redistribuição de renda no intuito de ampliar o acesso ao consumo privado, ela cobraria impostos aos mais ricos para reconstruir as instituições e os serviços públicos, para que ricos e pobres pudesse usufruir deles igualmente (SANDEL, 2012, p. 329).

Portanto, a ideia de república propõe a reconstrução de instituições e serviços públicos para que todos tenham espaços onde possam sentir-se iguais; propõe a utilização de meios que permitam satisfazer a virtude cívica, afastando as noções e práticas de vida puramente egoísta.

Liberais e republicanos apresentam, assim, modos de vida 
totalmente diferentes, como resultado da interpretação e da aplicação da autonomia privada. Os liberais, embora até falem em reduzir desigualdades, acabam demonstrando um modelo de sociedade na qual o Estado transfere recursos a indivíduos deixando-os servir como bem entendam, até mesmo egoistamente. Para os republicanos, os benefícios distribuídos pelo Estado destinam-se ao bem comum, ao bem de todos, para a construção de uma sociedade melhor, o que é muito diferente de destiná-los a indivíduos e deixar que eles os usem ao seu bel prazer. No primeiro caso, os bens distribuídos são entregues aos indivíduos; no segundo, para a sociedade como um todo. A aplicação das normas de defesa do consumidor, por exemplo, pode tornar-se uma guerra entre consumidor e produtor, sob o ponto de vista liberal, pois cada indivíduo deseja o seu sucesso, prometido pelo Estado; sob o ponto de vista republicano, é preciso buscar o bem comum, o bem de todos, numa relação de reciprocidade; produtores e consumidores devem solucionar o conflito de modo a aperfeiçoar a comunidade, buscando maior igualdade entre si.

Cercear a autonomia privada em benefício de outrem não significa proporcionar melhoria e progresso humano. Tirar de alguém para entregar a outrem um bem de vida pode ser apenas transferir de bens de vida, para que aquele que recebe possa buscar a sua felicidade, como bem entende; outra coisa é transferir bens de vida a aperfeiçoar as instituições e construir práticas sociais voltadas para todos os membros da comunidade. O paradigma moderno de negócio jurídico, pode ser justificado por ambas as concepções, a liberal e a republicana, dependendo única e exclusivamente, do fundamento que sustenta o atual modelo de negócio jurídico. 


\section{CONCLUSÃO}

Com o exposto pretendeu-se refletir sobre questões mais profundas do que a simples positivação das normas que regem o direito contratual de uma coletividade.

Buscou-se demonstrar, através do estudo da evolução do paradigma do negócio jurídico e do estudo da concepção liberal e republicana de liberdade, o quão importante é a compreensão do modelo de liberdade que a sociedade adota e a direta relação que isso guarda com a positivação e concretização dos negócios de um povo.

Graças aos estudos e análise da evolução do direito contratual no ordenamento jurídico brasileiro foi possível constatar que a sociedade brasileira, anteriormente à evolução do paradigma clássico para o moderno, possuía traços de um povo que exercia a liberdade de acordo com a concepção liberal.

Ou seja, o povo caracterizava-se por não se sujeitar à interferências do Estado nas questões que cabiam ao indivíduo; entende-se isso como exercício do sentido liberal de liberdade. Com a superação do paradigma clássico pelo moderno, foi possível de justificar

a incorporação dos direitos constitucionais ao direito civil brasileiro, tanto sob a perspectiva liberal, interpretada como a autonomia privada em benefício de indivíduos, quanto pela visão republicana, interpretada como a autonomia privada em benefício da sociedade como um todo. Uma sociedade justa requer uma preocupação com o todo.

\section{REFERÊNCIAS}

AMARAL, Francisco. Direito civil: introdução. 6. ed. Rio de Janeiro: Forense, 2003. 
BERLIN, Isaiah. Dois conceitos de liberdade. In: BERLIN, Isaiah. Estudos sobre a humanidade: uma antologia de ensaios. Tradução de Rosaura Eichenberg. São Paulo: Companhia das Letras, 2002.

BETTI, Emílio. Teoria geral do negócio jurídico. Coimbra: Coimbra Editora L.D.A, 1969.

CONSTANT, Benjamin. Da liberdade dos antigos comparada à dos modernos. In: MONTEIRO, João Paulo e outros. Filosofia Política 2. Porto Alegre: L\&PM Editores (UNICAMP/UFRGS - com apoio do CNPQ), 1985.

MORAES, Maria Celina Bodin de. A caminho de um direito civil constitucional. Revista Estado, Direito e Sociedade, v. I, 1991.

PEREIRA, Caio Mário da Silva. Instituições de direito civil: teoria geral do direito civil. 26. ed. Rio de Janeiro: Forense, 2013. v. 1.

RAMOS, César Augusto. A concepção republicana de liberdade como não-dominação. Crítica: Revista de Filosofia. Londrina, v.10, n. 32, p. 229-264, out./2007.

SANDEL, Michael J. Justiça: o que é fazer a coisa certa. Rio de Janeiro: Civilização Brasileira, 2012.

Como citar: SOARES, Marcos Antônio Striquer; PASSI, Renata Capriolli Zocatelli Queiroz. A superação do paradigma clássico do negócio jurídico: liberalismo e republicanismo. Scientia Iuris, Londrina, v. 21 , n. 1 , p. $245-268$, mar. 2017. DOI: $10.5433 / 2178-8189.2017 \mathrm{v} 21 \mathrm{n}$ 1p245. ISSN: 2178-8189.

Recebido em: 21/01/2017

Aprovado em: 26/03/2017 